\title{
Efficacy and Safety of CAR-Modified T Cell Therapy in Patients with Relapsed or Refractory Multiple Myeloma: A Meta-Analysis of Prospective Clinical Trials
}

\author{
Xinrong Xiang ${ }^{1+}$, Qiao $\mathrm{He}^{2 \dagger}$, Yang $\mathrm{Ou}^{1}$, Wen $\mathrm{Wang}^{2}$ and $\mathrm{Yu} \mathrm{Wu}^{1 *}$ \\ ${ }^{1}$ Hematology Research Laboratory, West China Hospital, Department of Hematology, Sichuan University, Chengdu, China, \\ ${ }^{2}$ Chinese Evidence-based Medicine Center and Cochrane China Center, West China Hospital, Sichuan University, Chengdu, \\ China
}

\section{OPEN ACCESS}

Edited by:

William Valentine Williams, BriaCell Therapeutics Corp.,

United States

Reviewed by: Angelique Nyinawabera, L.E.A.F. Pharmaceuticals, United States

Shikha Kumari,

University of Nebraska Medical

Center, United States

*Correspondence:

YuWu

wu_yu@scu.edu.cn

${ }^{+}$These authors have contributed equally to this work

Specialty section:

This article was submitted to Pharmacology of Anti-Cancer Drugs,

a section of the journal

Frontiers in Pharmacology

Received: 22 March 2020 Accepted: 16 October 2020 Published: 03 December 2020

Citation:

Xiang $X$, He Q, Ou Y, Wang W and Wu Y (2020) Efficacy and Safety of

CAR-Modified T Cell Therapy in Patients with Relapsed or Refractory Multiple Myeloma: A Meta-Analysis of

Prospective Clinical Trials.

Front. Pharmacol. 11:544754

doi: 10.3389/fphar.2020.544754
Background: In recent years, chimeric antigen receptor-modified T (CAR-T) cell therapy for B-cell leukemia and lymphoma has shown high clinical efficacy. Similar CAR-T clinical trials have also been carried out in patients with refractory/relapsed multiple myeloma (RRMM). However, no systematic review has evaluated the efficacy and safety of CAR-T cell therapy in RRMM. The purpose of this study was to fill this literature gap.

Methods: Eligible studies were searched in PUBMED, EMBASE, the Cochrane Central Register of Controlled Trials (CENTRAL), CNKI, and WanFang from data inception to December 2019. For efficacy assessment, the overall response rate (ORR), minimal residual disease (MRD) negativity rate, strict complete response (SCR), complete response (CR), very good partial response (VGPR), and partial response (PR) were calculated. The incidence of any grade cytokine release syndrome (CRS) and grade $\geq 3$ adverse events (AEs) were calculated for safety analysis. The effect estimates were then pooled using an inverse variance method.

Results: Overall, 27 studies involving 497 patients were included in this meta-analysis. The pooled ORR and MRD negativity rate were 89\% (95\% Cl: 83-94\%) and 81\% (95\% Cl: 67-91\%), respectively. The pooled sCR, CR, VGPR, and PR were 14\% (95\% Cl: 5-27\%), 13\% (95\% Cl: 4-26\%), 23\% (95\% Cl: 14-33\%), and 15\% (95\% Cl: 10-21\%), respectively. Subgroup analyses of ORR by age, proportion of previous autologous stem cell transplantation (ASCT), and target selection of CAR-T cells revealed that age $\leq$ 55 years ( $\leq 55$ years vs. $>55$ years, $p=0.0081$ ), prior $\mathrm{ASCT} \leq 70 \%(\leq 70 \%$ vs. $>70 \%$, $p=0.035)$, and bispecific CAR-T cells (dual B-cell maturation antigen (BCMA)/BCMA + CD19 vs specific BCMA, $p=0.0329$ ) associated with higher ORR in patients. Subgroup analyses of remission depth by target selection suggested that more patients achieved a better response than VGPR with dual BCMA/BCMA + CD19 CAR-T cells compared to specific BCMA targeting ( $p=0.0061)$. In terms of safety, the pooled incidence of any grade and grade $\geq 3$ CRS was 76\% (95\% CL: 63-87\%) and 11\% (95\% CL: 6-17\%). The most common grade $\geq 3$ AEs were hematologic toxic effects. 
Conclusion: In heavily treated patients, CAR-T therapy associates with promising responses and tolerable AEs, as well as CRS in RRMM. However, additional information regarding the durability of CAR-T cell therapy, as well as further randomized controlled trials, is needed.

Keywords: chimeric antigen receptor, cancer immunotherapy, multiple myeloma, efficacy, safety, meta-analysis

\section{INTRODUCTION}

Multiple myeloma (MM) is the second most common hematological malignancy after non-Hodgkin's lymphoma. It is characterized by clonal evolution of malignant plasma cells (Lipe et al., 2016). During the past decades, autologous stem cell transplantation (ASCT) and the development of novel agents, such as proteasome inhibitors (PIs), immunomodulatory drugs (IMiDs), and monoclonal antibodies, have significantly prolonged patient survival. Although MM treatment options have gradually improved, relapsed and refractory diseases are common (Palumbo and Anderson, 2011; Rajkumar, 2011; Chim et al., 2018; Goldschmidt et al., 2019). It is, therefore necessary to develop innovative treatment strategies to achieve long-term remission for patients with relapsed/refractory MM.

Chimeric antigen receptor (CAR)- $T$ cell therapy has shown the potential for inducing durable remission in certain hematologic malignancies (Makita et al., 2017; Mikkilineni and Kochenderfer, 2017; Neelapu et al., 2018). Meanwhile, anti-CD19 CAR-T-cell therapies reportedly offer promising efficacy in patients with leukemia or lymphoma. Based on previous successful results in B-cell neoplasms (Maude et al., 2014; Lee et al., 2015; Turtle et al., 2016a; Kochenderfer et al., 2017; Neelapu et al., 2017; Jain et al., 2018; Maude et al., 2018; Park et al., 2018), this approach has been licensed by the US Food and Drug Administration (FDA) for the treatment of relapsed or refractory acute lymphocytic leukemia (ALL), and diffuse large B-cell lymphoma (DLBCL). CAR-T cell therapy is defined as a novel immunotherapy that modifies T-cells with CAR, typically consisting of a target-recognition ectodomain, an anchored functional transmembrane domain, a hinge region, and signaling endodomains (Jensen and Riddell, 2015; van der Stegen et al., 2015; Guedan et al., 2018). Selection of targets is the key to successful CAR-T therapy (Melchor et al., 2014). Currently, in the context of RRMM, targets used in clinical trials include the B-cell maturation antigen (BCMA), CD19, CD138, signaling lymphocytic activation molecule 7 (SLAM7), immunoglobulin light chains, and the fully human heavy-chain variable domain (FHVH) (Hajek et al., 2013; Lam et al., 2020).

Design and optimization of CAR-T therapy in RRMM has been a hot research area with several prospective clinical trials having been conducted to evaluate its efficacy and safety. However, there is a lack of quantitative and comprehensive statistical analyses on treatment outcome. Moreover, the factors contributing to CAR-T-cell therapy efficacy and safety in RRMM patients remain unclear. Therefore, a systematic review and meta-analysis on the efficacy and safety of the CAR-modified $\mathrm{T}$ cell therapy in RRMM patients were performed to offer an evidence-based reference for clinicians.

\section{MATERIALS AND METHODS}

\subsection{Methods}

In performing this study, we abided by the standards set by the Preferred Reporting Items for Systematic Reviews and MetaAnalyses (PRISMA) (Knobloch et al., 2011).

\subsection{Literature Search}

We searched PUBMED, EMBASE, the Cochrane Central Register of Controlled Trials (CENTRAL), CNKI, and WanFang from inception of the study to December 20, 2019 without any language restriction. We combined Medical Subject Headings $(\mathrm{MeSH})$ terms and free-text terms regarding "CAR" and "myeloma" to search for potentially eligible studies.

\subsection{Inclusion and Exclusion Criteria}

We included clinical trials (phase 1 and phase 2 single arm trials) involving patients with relapsed or refractory $M M$ receiving CAR-T cell therapy. Qualified studies reported at least one of the following variables: efficacy outcomes (overall response rate, ORR), strict complete response (sCR), complete response (CR), very good partial response (VGPR), partial response (PR), minimal residual disease (MRD) negativity rate, and safety outcomes (any grade cytokine syndrome, CRS), grade $\geq 3$ AEs (anemia, neutropenia, lymphopenia, thrombocytopenia), and grade $\geq 3$ CAR-T- related encephalopathy syndrome (CRES). No restrictions on sample size or length of follow-up were imposed.

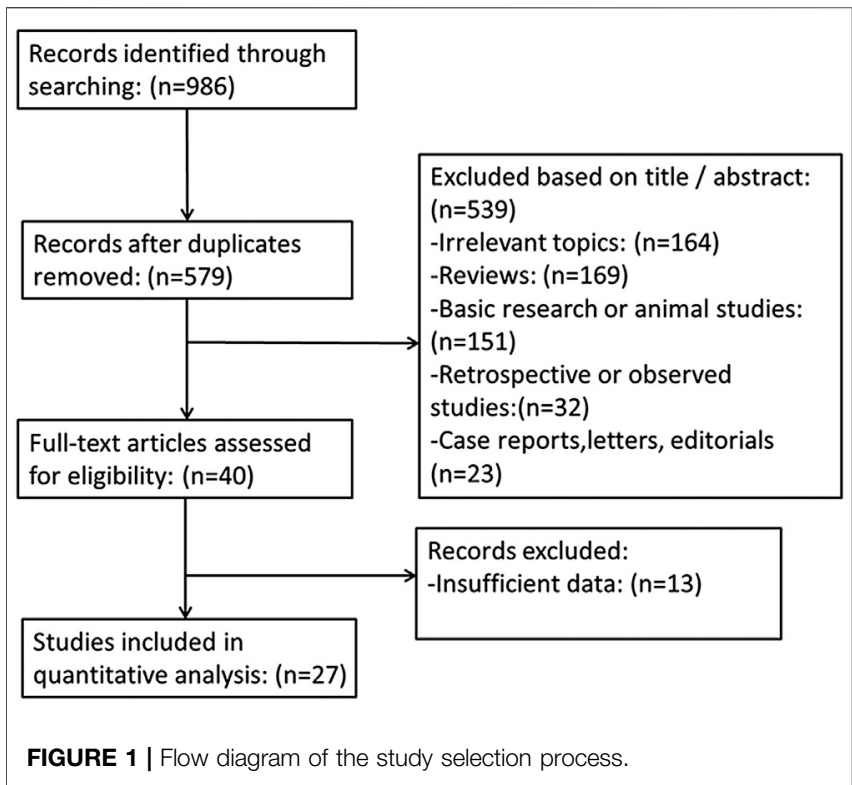


TABLE 1 | Characteristics of the included studies.

\begin{tabular}{|c|c|c|c|c|c|c|c|c|}
\hline No & Study & $\begin{array}{l}\text { Registration } \\
\text { number }\end{array}$ & $\begin{array}{c}\text { No. of } \\
\text { patients }\end{array}$ & Design & Target & Treatment & $\begin{array}{l}\text { Costimulatory } \\
\text { domain }\end{array}$ & Conditioning \\
\hline 1 & Raje et al. (2019) & NCT02658929 & 33 & Phase1, single arm & BCMA (bb2121) & $150 / 450 / 800 \times 106$ cells & $4-1 \mathrm{BB}$ & $\mathrm{CP} / \mathrm{Flu}$ \\
\hline 2 & $\begin{array}{l}\text { Brudno et al. } \\
(2018)\end{array}$ & NCT02215967 & 16 & Phase I, single arm & BCMA & $9 \times 106$ cells $/ \mathrm{kg}$ & CD28 & $\mathrm{CP} / \mathrm{Flu}$ \\
\hline 3 & Fan et al. (2017) & - & 19 & Phase $1 / I I$, single arm & LCAR-B38M & $4.7(0.6-7.0) \times 106 / \mathrm{kg}$ & 4-1BB & $\mathrm{CP}$ \\
\hline 4 & $\begin{array}{l}\text { Zhang et al. } \\
\text { (2017) }\end{array}$ & - & 22 & Phase I, single arm & LCAR-B38M & $4.0 \times 106(1.5-7.0 \times 106) / \mathrm{kg}$ & $4-1 B B$ & $\mathrm{CP}$ \\
\hline 5 & Hao et al. (2019) & $\begin{array}{l}\text { NCT03716856, NСT03302403, } \\
\text { NCT03380039 }\end{array}$ & 24 & 3-Site phase $\mathrm{I}$, single arm & BCMA ( СТ053) & $1.5 \times 108$ cells & $4-1 \mathrm{BB}$ & $\mathrm{CP} / \mathrm{Flu}$ \\
\hline 6 & Han et al. (2019) & - & 16 & Phase I, single arm & BCMA & $2-10 \times 106$ cells $/ \mathrm{kg}$ & 4-1BB & $\mathrm{CP} / \mathrm{Flu}$ \\
\hline 7 & Shah et al. (2020) & NCT03274219 & 22 & Multicenter phase I, single arm & $\begin{array}{l}\text { BCMA } \\
(\mathrm{bb} 21217)\end{array}$ & $150 / 300 / 450 \times 106$ cells & $4-1 B B$ & $\mathrm{CP} / \mathrm{Flu}$ \\
\hline 8 & Zhao et al. (2018) & NCT03090659 & 57 & Multisite phase $1 / 2$ & LCAR-B38M & $0.07-2.1 \times 106 \mathrm{celll} / \mathrm{kg}$ & $4-1 \mathrm{BB}$ & $\mathrm{CP}$ \\
\hline 9 & Jie et al. (2019) & ChiCTR-ONH-17012285 & 17 & Multisite phase $1 / 2$, single arm & LCAR-B38M & $0.21-1.52 \times 106$ cells $/ \mathrm{kg}$ & $4-1 B B$ & $\begin{array}{l}\text { CP/Flu or } \mathrm{CP} \\
\text { only }\end{array}$ \\
\hline 10 & $\begin{array}{l}\text { Gregory et al. } \\
\text { (2018) }\end{array}$ & NCT03288493 & 12 & Phase I, single arm & BCMA & $0.75-15 \times 106$ cells & $4-1 B B$ & CP/Flu \\
\hline 11 & $\begin{array}{l}\text { Mailankody et al. } \\
\text { (2018a) }\end{array}$ & NCT03430011 & 19 & Multisite phase $1 / 2$, single arm & BCMA & $50 / 150 \times 106$ cells $(5+3)$ & $4-1 \mathrm{BB}$ & $\mathrm{CP} / \mathrm{Flu}$ \\
\hline 12 & Jiang et al. (2018) & NCT03915184 & 16 & Multisite phase1(СТ053) & $\begin{array}{l}\text { BCMA (СТ053), } \\
\text { single arm }\end{array}$ & $0.5 / 1.5 / 1.8 \times 108$ cells & $4-1 \mathrm{BB}$ & $\mathrm{CP} / \mathrm{Flu}$ \\
\hline 13 & $\begin{array}{l}\text { Mailankody et al. } \\
\text { (2018b) }\end{array}$ & NCT03070327 & 11 & Phase 1 (MCARH171), single arm & BCMA & $72 / 137 / 475 / 818 \times 106$ cells & $4-1 B B$ & $\mathrm{CP} / \mathrm{Flu}$ \\
\hline 14 & Li et al. (2018) & ChiCTR-OPC-16009113 & 28 & Phase 1 (BRD015), single arm & BCMA & $5.4-25.0 \times 106 \mathrm{cells} / \mathrm{kg}$ & CD28 & CP/Flu \\
\hline 15 & Li et al. (2019a) & ChiCTR1800018137 & 16 & Phase 1 (CT103A), single arm & BCMA & $1 / 3 / 6 / 8 \times 106 \mathrm{cell} / \mathrm{s} / \mathrm{kg}$ & $4-1 \mathrm{BB}$ & $\mathrm{CP} / \mathrm{Flu}$ \\
\hline 16 & $\begin{array}{l}\text { Cohen et al. } \\
\text { (2019) }\end{array}$ & NCT02546167 & 25 & Single arm phase 1 & BCMA & $1-5 \times 107 / 108$ cells & $4-1 \mathrm{BB}$ & $\mathrm{CP}$ or none \\
\hline 17 & Fu et al. (2019) & NCT03093168 & 44 & Single arm phase 1 & BCMA & $9 \times 106$ cells $/ \mathrm{kg}$ & 4-1BB & $\mathrm{CP} / \mathrm{Flu}$ \\
\hline 18 & Han et al. (2018) & NCT03661554 & 4 & Multisite phase 1 ; single arm & BCMA & $5 / 10 \times 106 \mathrm{cells} / \mathrm{kg}$ & $4-1 \mathrm{BB}$ & CP/Flu \\
\hline 19 & Yan et al. (2017) & NCT03196414 & 8 & Single arm & $\mathrm{BCMA}+\mathrm{CD} 19$ & $\begin{array}{l}1 \times 107 / \mathrm{kg} \text { CD19-targeted cells; } \\
2.5-8.2 \times 107 / \mathrm{kg} \mathrm{BCMA-targeted} \mathrm{cells}\end{array}$ & OX40, CD28 & $\mathrm{CP} / \mathrm{Flu}$ \\
\hline 20 & Shi et al. (2018) & NCT03455972 & 9 & Single arm & $\mathrm{BCMA}+\mathrm{CD} 19$ & $\begin{array}{l}1 \times 107 / \mathrm{kg} \text { CD19-targeted cells; } \\
2.5-8.2 \times 107 / \mathrm{kg} \mathrm{BCMA-targeted} \mathrm{cells}\end{array}$ & OX40, CD28 & $\mathrm{BUCY}+\mathrm{ASCT}$ \\
\hline 21 & Yan et al. (2019) & ChiCTR-OIC-17011272 & 21 & Single arm, phase 2 trial & $\mathrm{BCMA}+\mathrm{CD} 19$ & $\begin{array}{l}1 \times 106 / \mathrm{kg} \text { both BCMA and CD19- } \\
\text { targeted CAR + T cells }\end{array}$ & $4-1 B B$ & $\mathrm{CP} / \mathrm{Flu}$ \\
\hline 22 & Damian (2018) & NCT03338972 & 7 & Phase I, single arm & BCMA & $5-15 \times 107$ cells & $4-1 \mathrm{BB}$ & Null \\
\hline 23 & $\begin{array}{l}\text { Cowan et al. } \\
\text { (2019) }\end{array}$ & NCT03502577 & 6 & $\begin{array}{l}\text { Phase I single arm, with an orally administered } \\
\text { gamma secretase inhibitor (JSMD194) }\end{array}$ & BCMA? & $5 \times 107$ EGFRt + cells & $4-1 B B$ & Null \\
\hline 24 & $\begin{array}{l}\text { Madduri et al. } \\
\text { (2019) }\end{array}$ & NCT03548207 & 25 & $\begin{array}{l}\text { Phase } 1 \mathrm{~b} / 2 \text { single arm study of JNJ-4528 } \\
\text { (containing two BCMA targeting) }\end{array}$ & BCMA & $0.75 \times 106 \mathrm{cells} / \mathrm{kg}(0.5-1.0 \times 106)$ & Null & $\mathrm{CP} / \mathrm{Flu}$ \\
\hline 25 & Li et al. (2019b) & ChiCTR1800018143 & 16 & Phase 1 single arm (BM38) & $\mathrm{BCMA}+\mathrm{CD} 38$ & 0.5/1.0/2.0/3.0/4.0 × 106 cells $/ \mathrm{kg}$ & $4-1 \mathrm{BB}$ & $\mathrm{CP} / \mathrm{Flu}$ \\
\hline 26 & Popat et al. (2019) & - & 12 & $\begin{array}{l}\text { Phase } 1 \text { first-in-human study of AUTO2, single } \\
\text { arm }\end{array}$ & $\mathrm{BCMA}+\mathrm{TACl}$ & $15 / 75 / 225 / 600 / 900 \times 106$ cells & CD28 & $\mathrm{CP} / \mathrm{Flu}$ \\
\hline 27 & $\begin{array}{l}\text { Mikkilineni et al. } \\
\text { (2019) }\end{array}$ & - & 12 & Single arm & FHVH-BCMA-T & $0.75 / 1.5 / 3 \times 106$ cells $/ \mathrm{kg}$ & 4-1BB & $\mathrm{CP} / \mathrm{Flu}$ \\
\hline
\end{tabular}

BCMA,B-cell maturation antigen; FHVH, fully human heavy-chain variable domain; LCAR-B38M, bispecific BCMA; TACI, transmembrane activator and calcium-modulator and cyclophilin ligand interactor; CP,cyclophosphamide; Flu,fludarabine; mAb, monoclonal antibody; ASCT, autologous stem cell transplant. 
TABLE 2 | Characteristics of the included patients.

\begin{tabular}{|c|c|c|c|c|c|c|c|c|c|}
\hline No & Study & $\begin{array}{c}\text { No. of } \\
\text { patients }\end{array}$ & $\begin{array}{c}\text { Mean } \\
\text { age (years) }\end{array}$ & $\begin{array}{l}\text { prior } \\
\text { lines }\end{array}$ & $\begin{array}{l}\text { median } \\
\text { time } \\
\text { from } \\
\text { diagnosis, } \\
\text { (years) }\end{array}$ & $\begin{array}{l}\text { High-risk- } \\
\text { cytogenetics } \\
(\%)\end{array}$ & $\begin{array}{c}\text { Prior } \\
\text { ASCT } \\
(\%)\end{array}$ & $\begin{array}{c}\text { Anti-CD38 } \\
\text { mAb exposed } \\
(\%)\end{array}$ & $\begin{array}{c}\text { Extramedullary- } \\
\text { disease } \\
(\%)\end{array}$ \\
\hline 1 & Raje et al. (2019) & 33 & 60 & 7 & 5 & $45.00 \%$ & $97.00 \%$ & $79.00 \%$ & $27.00 \%$ \\
\hline 2 & Brudno et al. (2018) & 16 & - & 9.5 & - & $40.00 \%$ & $75.00 \%$ & $43.75 \%$ & - \\
\hline 3 & Fan et al. (2017) & 19 & - & - & - & - & - & - & - \\
\hline 4 & Zhang et al. (2017) & 22 & 53.5 & - & - & - & $18.20 \%$ & - & - \\
\hline 5 & Hao et al. (2019) & 24 & 60.1 & 4.5 & 3.5 & $37.50 \%$ & $41.70 \%$ & $20.80 \%$ & $45.80 \%$ \\
\hline 6 & Han et al. (2019) & 16 & - & 10 & - & - & - & - & $18.75 \%$ \\
\hline 7 & Shah et al. (2020) & 22 & 63 & 7 & - & $31.82 \%$ & $82.00 \%$ & $86.00 \%$ & - \\
\hline 8 & Zhao et al. (2018) & 57 & 54 & 3 & 4 & - & $58.00 \%$ & $0.00 \%$ & - \\
\hline 9 & Jie et al. (2019) & 17 & 56 & 4 & - & - & $47.05 \%$ & - & $29.41 \%$ \\
\hline 10 & Gregory et al. (2018) & 12 & - & - & - & $64.00 \%$ & - & $100.00 \%$ & - \\
\hline 11 & Mailankody et al. (2018a) & 19 & 53 & 10 & 4 & $50.00 \%$ & $88.00 \%$ & - & - \\
\hline 12 & Jiang et al. (2018) & 16 & 55 & 4 & 3.9 & - & $56.00 \%$ & - & - \\
\hline 13 & Mailankody et al. (2018b) & 11 & - & 6 & - & $82.00 \%$ & - & $100.00 \%$ & - \\
\hline 14 & Li et al. (2018) & 28 & - & - & - & - & - & - & - \\
\hline 15 & Li et al. (2019a) & 16 & - & - & - & - & - & - & - \\
\hline 16 & Cohen et al. (2019) & 25 & 58 & 7 & 4.6 & $96.00 \%$ & $92.00 \%$ & $76.00 \%$ & $28.00 \%$ \\
\hline 17 & Fu et al. (2019) & 44 & - & - & - & - & - & - & - \\
\hline 18 & Han et al. (2018) & 4 & 57 & - & - & - & - & - & - \\
\hline 19 & Yan et al. (2017) & 8 & - & 4 & - & - & - & - & - \\
\hline 20 & Shi et al. (2018) & 9 & 55 & - & - & - & - & - & - \\
\hline 21 & Yan et al. (2019) & 21 & - & - & - & - & - & - & - \\
\hline 22 & Damian (2018) & 7 & 63 & 8 & - & $100.00 \%$ & $71.00 \%$ & - & - \\
\hline 23 & Cowan et al. (2019) & 6 & 64.5 & 10 & - & $75.00 \%$ & - & - & - \\
\hline 24 & Madduri et al. (2019) & 25 & 61 & 5 & - & - & - & $100.00 \%$ & - \\
\hline 25 & Li et al. (2019b) & 16 & 61 & - & - & - & - & - & $31.25 \%$ \\
\hline 26 & Popat et al. (2019) & 12 & 61 & 5 & - & - & $73.00 \%$ & - & - \\
\hline 27 & Mikkilineni et al. (2019) & 12 & 63 & 6 & - & - & - & - & - \\
\hline
\end{tabular}

BCMA,B-cell maturation antigen; FHVH, fully human heavy-chain variable domain; LCAR-B38M, bispecific BCMA; TACI, transmembrane activator and calcium-modulator and cyclophilin ligand interactor; CP,cyclophosphamide; Flu,fludarabine; $m A$, monoclonal antibody; ASCT, autologous stem cell transplant.

\subsection{Study Qualitative Assessment}

The Methodological Index for Non-randomized Studies (MINORS) was adopted to assess the methodological quality of the inclusive studies. MINORS contained 12 items, eight of which were specified for non-comparative studies (Slim et al., 2003; Cullis et al., 2020). The eight items included: study aims, consecutive patient inclusion criteria, prospective pooling of data, endpoint consistent with the study aim, unbiased evaluation of endpoints, follow-up period, loss to follow-up less than $5 \%$, and prospective calculation of the sample size. The items were scored 0 (not reported), 1 (reported but inadequate), or 2 (reported and adequate).

\subsection{Data Extraction}

Two investigators independently reviewed and extracted the following information: study characteristics (first author, publication year, ClinicalTrials.gov number, research design), patient characteristics (the group number, age, median time from diagnosis, prior lines of treatment, high-risk cytogenetics, previous ASCT, anti-CD38 monoclonal antibodies exposed, extramedullary-disease), intervention (CAR-T cell dose, target selection, costimulatory domain, conditioning regimen), and outcomes of interest (treatment response, adverse events
(AEs)). Discrepancies were settled by discussion or by adjudication by a third reviewer.

\subsection{Statistical Analysis}

We used the Metaprop module in the R-3.4.3 statistical software package to analyze therapeutic efficacy and safety. The effect estimates were pooled using an inverse variance method. Heterogeneity among studies was evaluated by the chi-squared test $\left(\chi^{2}\right.$ test) and I-squared test $\left(I^{2}\right.$ test). In case of potential heterogeneity $\left(I^{2}>50 \%\right)$, analysis was conducted using the random-effect model; otherwise, the fixed-effect model was employed. Subgroup analysis by age ( $\leq 55$ vs. $>55$ years), proportion of high-risk cytogenetics $(\leq 50 \%$ vs. $>50 \%)$, proportion of previous ASCT ( $\leq 70 \%$ vs. $>70 \%)$, conditioning regimen (cyclophosphamide plus fludarabine vs cyclophosphamide only), target selection for CAR-T therapy (specific BCMA vs. dual BCMA/BCMA + CD19 vs BCMA + others), costimulatory domain (4-1BB vs. CD28 vs. CD28+ OX40) was performed to explore the sources of heterogeneity. $P$ values $<0.05$ were considered statistically significant. Sensitivity analysis was aimed at estimating the effect with removal of the largest sample size among all studies. 
TABLE 3 | The scores of MINORS.

\begin{tabular}{|c|c|c|c|c|c|c|c|c|c|}
\hline Study & 1 & 2 & 3 & 4 & 5 & 6 & 7 & 8 & Total \\
\hline Raje et al. (2019) & 2 & 2 & 2 & 2 & 2 & 2 & 2 & 0 & 14 \\
\hline Brudno et al. (2018) & 2 & 2 & 2 & 2 & 2 & 2 & 2 & 2 & 16 \\
\hline Fan et al. (2017) & 2 & 2 & 2 & 2 & 2 & 2 & 2 & 0 & 14 \\
\hline Zhang et al. (2017) & 2 & 2 & 2 & 2 & 2 & 2 & 2 & 0 & 14 \\
\hline Hao et al. (2019) & 2 & 2 & 2 & 2 & 2 & 0 & 2 & 0 & 12 \\
\hline Han et al. 2019 & 2 & 2 & 2 & 2 & 2 & 2 & 2 & 0 & 14 \\
\hline Shah et al. (2020) & 2 & 2 & 2 & 2 & 2 & 2 & 2 & 0 & 14 \\
\hline Zhao et al. (2018) & 2 & 2 & 2 & 2 & 2 & 2 & 2 & 0 & 14 \\
\hline Jie et al. (2019) & 2 & 2 & 2 & 2 & 2 & 2 & 2 & 0 & 14 \\
\hline Gregory et al. (2018) & 2 & 2 & 2 & 2 & 2 & 2 & 0 & 0 & 12 \\
\hline Mailankody et al. (2018) & 2 & 0 & 2 & 2 & 0 & 0 & 0 & 0 & 6 \\
\hline Jiang et al. (2018) & 2 & 0 & 2 & 2 & 2 & 0 & 0 & 0 & 8 \\
\hline Mailankody et al. (2018) & 2 & 0 & 2 & 2 & 2 & 0 & 2 & 0 & 10 \\
\hline Li et al. (2018) & 2 & 0 & 2 & 2 & 0 & 0 & 2 & 0 & 8 \\
\hline Li et al. (2019a) & 2 & 2 & 2 & 2 & 2 & 2 & 2 & 0 & 14 \\
\hline Cohen et al. (2019) & 2 & 2 & 2 & 2 & 2 & 2 & 2 & 0 & 14 \\
\hline Fu et al. (2019) & 2 & 2 & 2 & 2 & 2 & 2 & 2 & 0 & 14 \\
\hline Han et al. (2018) & 2 & 0 & 2 & 2 & 2 & 2 & 2 & 0 & 12 \\
\hline Yan et al. (2017) & 2 & 2 & 2 & 2 & 2 & 2 & 0 & 0 & 12 \\
\hline Shi et al. (2018) & 2 & 0 & 2 & 2 & 2 & 0 & 2 & 0 & 10 \\
\hline Yan et al. (2019) & 2 & 2 & 2 & 2 & 2 & 2 & 2 & 0 & 14 \\
\hline Damian (2018) & 2 & 0 & 2 & 2 & 2 & 0 & 2 & 0 & 10 \\
\hline Cowan et al. (2019) & 2 & 2 & 2 & 2 & 2 & 2 & 2 & 0 & 14 \\
\hline Madduri et al. (2019) & 2 & 2 & 2 & 2 & 2 & 2 & 2 & 0 & 14 \\
\hline Li et al. (2019b) & 2 & 2 & 2 & 2 & 2 & 2 & 2 & 0 & 14 \\
\hline Popat et al. (2019) & 2 & 2 & 2 & 2 & 2 & 2 & 2 & 0 & 14 \\
\hline Mikkilineni et al. (2019) & 2 & 2 & 2 & 2 & 0 & 2 & 2 & 0 & 12 \\
\hline
\end{tabular}

\section{RESULTS}

\subsection{Literature Search Results and Study Characteristics}

The flowchart illustrating the literature search process is presented in Figure 1. Our search yielded 986 reports, 407 of which were, duplicates. After screening titles, abstracts, and full text, 552 publications were excluded. Ultimately, 27 studies, involving 497 patients, were included (Fan et al., 2017; Yan et al., 2017; Zhang et al., 2017; Brudno et al., 2018; Zhao et al., 2018; Berdeja et al., 2019; Chen et al., 2019; Cohen et al., 2019; Costello et al., 2019; Cowan et al., 2019; Fu et al., 2019; Han et al., 2019; Jie et al., 2019; Li et al., 2019a; Li et al., 2019b; Madduri et al., 2019; Mikkilineni et al., 2019; Popat et al., 2019; Raje et al., 2019; Yan et al., 2019) (Mailankody et al., 2018a; Mailankody et al., 2018b; Damian et al., 2018; Han et al., 2018; Jiang et al., 2018; Li et al., 2018; Shi et al., 2018).

Table 1 shows the characteristics of the inclusive studies. All studies were single-arm clinical trials, and involved 497 patients who had received at least two lines of treatment. Of the 27 included studies, 17 (63\%) explored the efficacy and safety of the specific BCMA CAR-T therapy in patients with RRMM (Zhang et al., 2017; Brudno et al., 2018; Cohen et al., 2019; Costello et al., 2019; Cowan et al., 2019; Fu et al., 2019; Jie et al., 2019; Li et al., 2019b; Madduri et al., 2019; Popat et al., 2019; Raje et al., 2019) (Damian et al., 2018; Han et al., 2018; Jiang et al., 2018; Li et al., 2018; Mailankody et al., 2018a; Mailankody et al., 2018b), four (15\%) focused on targeting of the dual BCMA (Fan et al., 2017; Zhang et al., 2017; Zhao et al., 2018; Chen et al., 2019), three (11\%) explored the targeting of BCMA plus CD19 (Yan et al., 2017; Yan et al., 2019) (Shi et al., 2018), and the remaining three (11\%) examined the targeting of BCMA plus other targets, i.e., $\mathrm{CD} 38, \mathrm{FHVH}$, and the transmembrane activator and calcium-modulator and cyclophilin ligand interactor (TACI), respectively (Li et al., 2019a; Mikkilineni et al., 2019; Popat et al., 2019). The CAR-T cell dose varied across studies and ranged between $0.07 \times 10^{6}$ and $82 \times 10^{6}$ cells $/ \mathrm{kg}$. The costimulatory domain was either $4-1 \mathrm{BB}$ or CD28. For conditioning regimen, the common choices were cyclophosphamide (CP) alone or in combination with fludarabine (Flu). The mean patient age ranged from 53 to 64.5 years; the median time from diagnosis was 3.5-5 years; the proportion of anti-CD38 mAb exposure was $20.80-100 \%$; the proportion of prior ASCT was 18.20-97\%; the proportion of extramedullary-disease was $18.75-45.80 \%$; and the proportion of high-risk patients was $32-100 \%$ (Table 2).

\subsection{Study Quality}

All studies illustrated the aim of the study. Their endpoint was appropriate to the aim of the study and data were prospectively collected. In most studies (approximately 80\%) consecutive patients were enrolled, an unbiased evaluation of endpoints was performed, and loss to follow-up did not exceed $5 \%$. Twenty-six studies (96\%) did not prospectively calculate the sample size. In general, the overall rating was high, and the overall quality of the selected studies was adequate (Table 3).

\subsection{Efficacy of the CAR-Modified T Cell Therapy}

Twenty-seven studies with 497 patients reported ORR; the pooled ORR was $89 \%$ (95\% Cl: 83-94\%; Figure 2). Fifteen studies reported the minimal residual disease status, and the pooled MRD negativity rate was $81 \%$ (95\% Cl: 67-91\%) among 239 patients who responded to CAR-T therapy (Figure 2) (Fan et al., 2017; Brudno et al., 2018; Zhao et al., 2018; Berdeja et al., 2019; Chen et al., 2019; Cohen et al., 2019; Jie et al., 2019; Li et al., 2019a; Li et al., 2019b; Madduri et al., 2019; Mikkilineni et al., 2019; Raje et al., 2019) (Damian et al., 2018; Jiang et al., 2018; Shi et al., 2018). Eighteen studies with 339 patients reported the response depth (sCR, CR, VGPR, PR) (Fan et al., 2017; Zhang et al., 2017; Brudno et al., 2018; Berdeja et al., 2019; Chen et al., 2019; Cohen et al., 2019; Jie et al., 2019; Li et al., 2019a; Li et al., 2019b; Madduri et al., 2019; Mikkilineni et al., 2019; Raje et al., 2019) (Damian et al., 2018; Jiang et al., 2018; Shi et al., 2018). The pooled sCR, CR, VGPR, and PR were 14\% (95\% Cl: 5-27\%), 13\% (95\% Cl: 4-26\%), $23 \%$ (95\% Cl: $14-33 \%)$, and 15\% (95\% Cl: 10-21\%), respectively (Figure 3).

Subgroup analysis of ORR by age showed that, in patients with mean age $\leq 55$ years, the ORR was higher than in those with $>55$ years $(98.01 \%$ vs. $82.58 \%$, interaction $p=0.0081)$. Compared to the proportion of prior ASCT $>70 \%$, a higher ORR was observed with a higher proportion of prior ASCT $\leq 70 \%(93.68 \%$ vs. $76.12 \%$, interaction $p=0.035)$. Regarding target selection, the ORR obtained by targeting dual BCMA or BCMA + CD19 was 
A

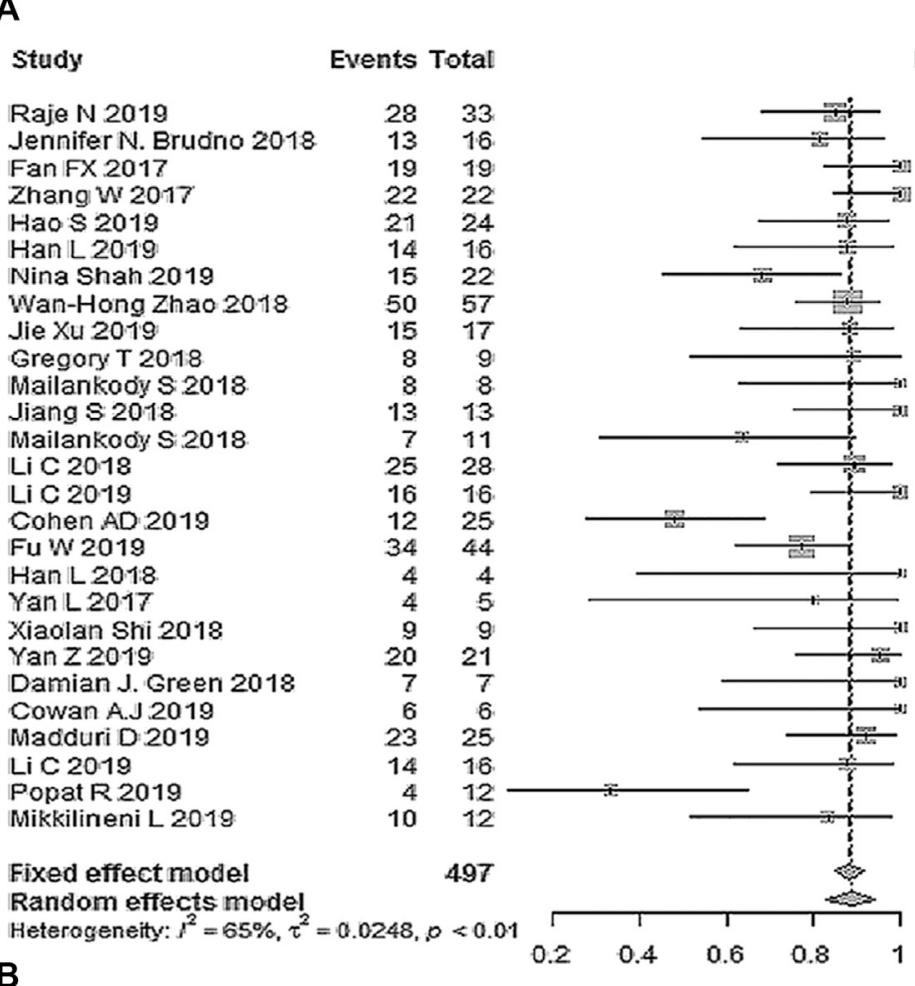

Weight veight

Raje N 2019

Fan FX 2017

Zhang W 2017

Jie Xu 2019

Mailankooy S 2018

Li C 2018

Li C 2019

Yan Z 2019

Damian J. Green 2018

Cowan A.J 2019

Li C 2019

Popat R 2019

Study

Events Total

$0.81[0.54 ; 0.96] \quad 3.2 \% \quad 3.8 \%$

1.00 [0.82: 1.00$] \quad 3.8 \% \quad 4.1 \%$

1.00 [0.85; 1.00$] \quad 4.4 \% \quad 4.2 \%$

$0.88[0.68 ; 0.97] \quad 4.8 \% \quad 4.4 \%$

$0.88[0.62 ; 0.98] \quad 3.2 \% \quad 3.8 \%$

$0.68 \cdot[0.45 ; 0.86] \quad 4.4 \% \quad 4.2 \%$

$0.88[0.76 ; 0.95] 11.3 \% \quad 5.2 \%$

0.88 [0.64;0.99] $3.4 \% \quad 3.9 \%$

$0.89[0.52 ; 1.00] \quad 1.9 \% \quad 3.0 \%$

1.00 [0.63; 1.00$] \quad 1.7 \% \quad 2.8 \%$

$1.00[0.75 ; 1.00] \quad 2.6 \% \quad 3.5 \%$

$0.64[0.31 ; 0.89] \quad 2.3 \% \quad 3.3 \%$

$0.89 \quad[0.72 ; 0.98] \quad 5.6 \% \quad 4.5 \%$

$1.00[0.79 ; 1.00] \quad 3.2 \% \quad 3.8 \%$

$0.48 \quad[0.28 ; 0.69] \quad 5.0 \% \quad 4.4 \%$

$0.77[0.62 ; 0.89] \quad 8.7 \% \quad 5.0 \%$

1.00 [0.40; 1.00$] \quad 0.9 \% \quad 1.9 \%$

$0.80[0.28 ; 0.99] \quad 1.1 \% \quad 2.2 \%$

$1.00[0.66 ; 1.00] \quad 1.9 \%-3.0 \%$

$0.95[0.76: 1.00] \quad 4.2 \% \quad 4.2 \%$

$1.00[0.59 ; 1.00] \quad 1.5 \% \quad 2.6 \%$

$1.00[0.54 ; 1.00] \quad 1.3 \% \quad 2.4 \%$

$0.92[0.74 ; 0.99] \quad 5.0 \% \quad 4.4 \%$

$0.88 \cdot[0.62 ; 0.98] \quad 3.2 \% \quad 3.8 \%$

0.33 [0.10; 0.65$] \quad 2.4 \% \quad 3.4 \%$

$0.83[0.52 ; 0.98] \quad 2.4 \% \quad 3.4 \%$

$\begin{array}{lll}0.88:[0.85 ; 0.91] & 100.0 \% & - \\ 0.89[0.83 ; 0.94] & - & 100.0 \%\end{array}$

Raje N 2019

Jennifer N. Bruơno 2018

Fan FX.2017

Hao $\$ 2019$

Nina Shah 2019

Wan-Hong Zhao 2018

Jie Xu 2019

Li C 2019

Cohen AD-1 2019

Cohen AD-3 2019

Xiaolan Shi 2018

Damian J. Green 2018

Cowan A.J 2019

Madduri D 2019

Li C 2019

Mikkilineni L 2019

$\begin{array}{rr}16 & 18 \\ 11 & 16 \\ 6 & 7 \\ 17 & 20 \\ 10 & 10 \\ 36 & 57 \\ 14 & 17\end{array}$

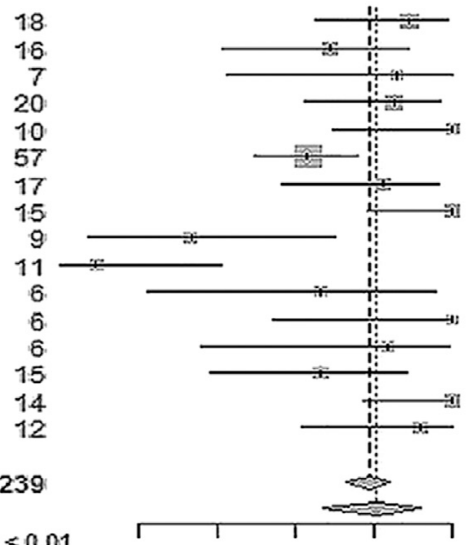

Proportion

Weight Meight

0.89 [0.65; 0.99 ] $7.5 \%$

$6.7 \%$

$5.4 \%$

$0.85[0.62 ; 0.97] \quad 8.3 \% \quad 7.0 \%$

$1.00[0.69 ; 1.00] \quad 4.3 \% \quad 6.0 \%$

0.63 [0.49; 0.76 ] $23.3 \% \quad 7.9 \%$

$0.82[0.57 ; 0.98] \quad 7.1 \% \quad 6.8 \%$

$1.00[0.78 ; 1.00] \quad 6.3 \% \quad 6.6 \%$

$0.33[0.07 ; 0.70] \quad 3.8 \% \quad 5.8 \%$

0.09 [0.00; 0.41$] \quad 4.7 \% \quad 6.2 \%$

$0.67[0.22 ; 0.96] \quad 2.6 \% \quad 5.1 \%$

$1.00[0.54 ; 1.00] \quad 2.6 \% \quad 5.1 \%$

$0.83[0.36 ; 1.00] 2.6 \% \quad 5.1 \%$

0.67 [0.38; 0.88$] \quad 6.3 \% \quad 6.6 \%$

$1.00[0.77 ; 1.00] \quad 5.9 \% \quad 6.5 \%$

$0.92[0.62 ; 1.00] \quad 5.1 \% \quad 6.3 \%$

$\begin{array}{lll}0.79[0.73 ; 0.84] & 100.0 \% \\ 0.81[0.67 ; 0.91] & -- & 100.0 \%\end{array}$

Fixed effect model
Random effects mode

Heteraceneitu: $I^{2}=77 \%, \tau^{2}=0.0570 .0 \leqslant 0.01$

FIGURE 2 | The forest plot of (A) pooled ORR, and (B), MRD negativity in patients who received CAR-T cell therapy.

higher than that obtained by targeting specific BCMA or BCMA plus other antigens $(96.05 \%$ vs. $86.18 \%$ vs. $70.28 \%$, interaction $p=$ 0.0329). However, subgroup analysis of ORR suggested that no significant differences occurred in the proportion of high-risk cytogenetics patients $(\leq 50 \%$ vs. $>50 \%)$, the use of different costimulatory domains (4-1BB vs CD28 vs CD28 + OX40), or in patients pretreated with $\mathrm{CP}$ in the presence or absence of Flu (Table 4). Subgroup analysis of remission depth (sCR, CR, VGPR, PR) suggested that compared to targeting specific BCMA, a higher proportion of patients achieved a better response than VGPR in the case of dual BCMA or BCMA +
CD19 targeting (59.89\% vs. $84.82 \%$, interaction $\mathrm{p}=0.0061)$. These results are shown in Figure 4 and Table 5.

\subsection{Safety of the CAR-Modified T Cell Therapy}

Twenty-four studies reported any grade CRS, and the total incidence of any grade CRS was 76\% (95\% CL: 63-87\%) (Fan et al., 2017; Yan et al., 2017; Brudno et al., 2018; Zhao et al., 2018; Berdeja et al., 2019; Chen et al., 2019; Cohen et al., 2019; Costello et al., 2019; Cowan et al., 2019; Fu et al., 2019; Han et al., 2019; Jie 


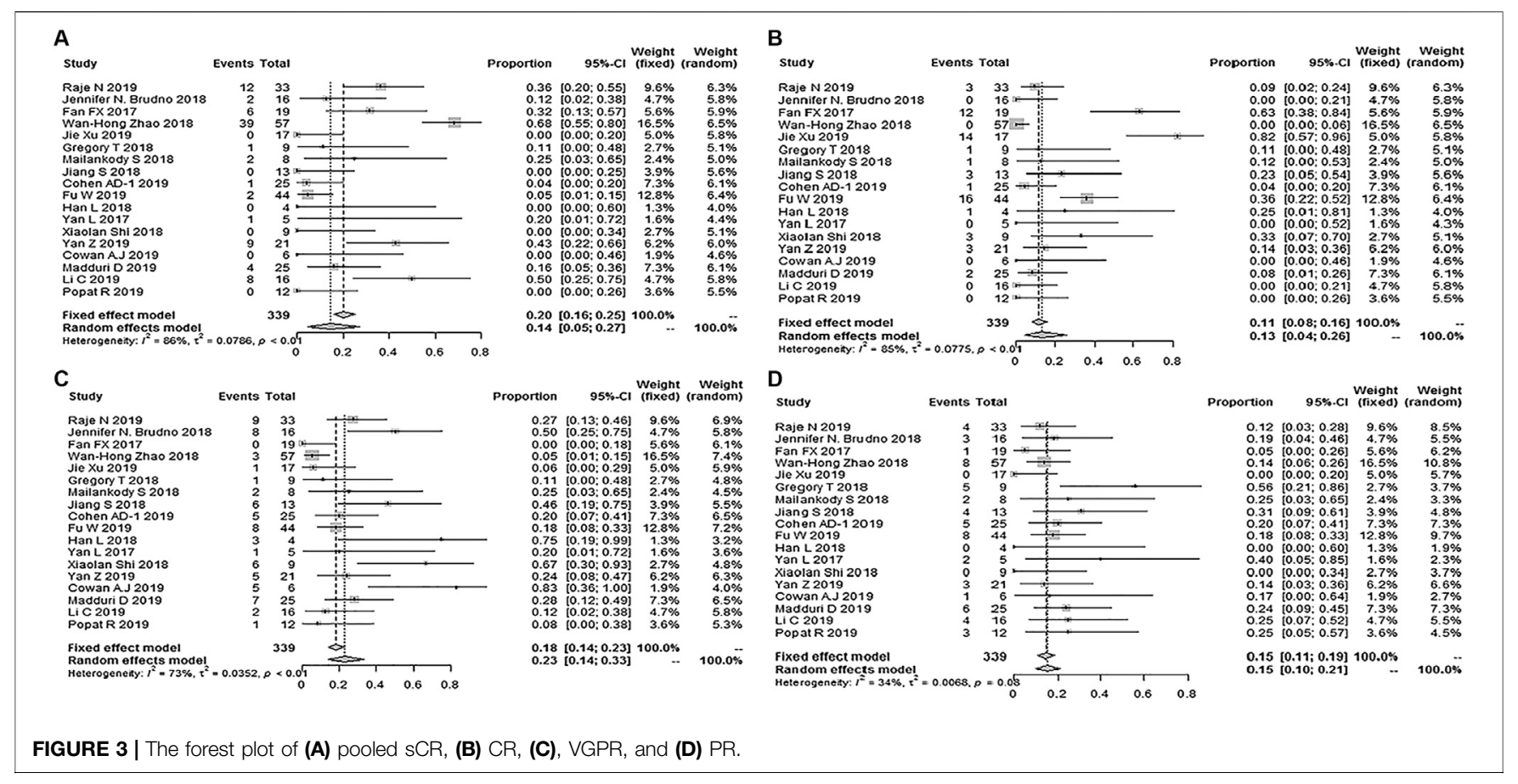

TABLE 4 | Subgroup analysis results of ORR.

\begin{tabular}{|c|c|c|c|}
\hline Subgroup & No of trails & ORR (95\% Cl) & $p$ for differences \\
\hline$\leq 55$ & 5 & 0.9801 [0.9099; 1.00] & \\
\hline \multicolumn{4}{|l|}{ High-risk cytogenetics (\%) } \\
\hline$\leq 50 \%$ & 5 & $0.8421[0.7421 ; 0.9237]$ & \\
\hline$>50 \%$ & 5 & $0.8217[0.5556 ; 0.9909]$ & 0.7841 \\
\hline \multicolumn{4}{|l|}{ Previous ASCT, rate (\%) } \\
\hline \multicolumn{4}{|l|}{ Condition regimen } \\
\hline $\mathrm{CP}$ & 5 & 0.8632 [0.6256; 0.9981] & \\
\hline $\mathrm{CP} / \mathrm{Flu}$ & 19 & $0.8680[0.8013 ; 0.9247]$ & 0.9628 \\
\hline \multicolumn{4}{|l|}{ CAR-T target } \\
\hline BCMA & 19 & 0.8618 [0.7842; 0.9269] & \\
\hline BCMA + CD19/bispecific BCMA & 7 & $0.9605[0.8964 ; 0.9979]$ & \\
\hline $4-1 B B$ & 21 & 0.9024 [0.8382; 0.9542] & \\
\hline CD28 & 3 & 0.7149 [0.3723; 0.9642] & \\
\hline OX40, CD28 & 2 & $0.9559[0.6435 ; 1.0000]$ & 0.4385 \\
\hline
\end{tabular}

et al., 2019; Li et al., 2019a; Li et al., 2019b; Madduri et al., 2019; Popat et al., 2019; Raje et al., 2019; Yan et al., 2019; Shah et al., 2020) (Damian et al., 2018; Han et al., 2018; Jiang et al., 2018; Mailankody et al., 2018a; Mailankody et al., 2018b; Shi et al., 2018). Twenty-five studies reported grade $\geq 3$ CRS, and the pooled incidence of grade $\geq 3$ CRS was $11 \%$ (95\% CL: 6-17\%) (Fan et al., 2017; Yan et al., 2017; Brudno et al., 2018; Zhao et al., 2018; Berdeja et al., 2019; Chen et al., 2019; Cohen et al., 2019; Costello et al., 2019; Cowan et al., 2019; Fu et al., 2019; Han et al., 2019; Jie et al., 2019; Li et al., 2019a; Li et al., 2019b; Madduri et al., 2019; Popat et al., 2019; Raje et al., 2019; Yan et al., 2019; Shah et al., 2020) (Damian et al., 2018; Han et al., 2018; Jiang et al., 2018; Li et al., 2018; Mailankody et al., 2018a; Mailankody et al., 2018b; Shi et al., 2018). Six studies reported a severe CRES, and the relevant pooled incidence was 8\% (95\% CL: 4-13\%) (Brudno et al., 2018; Berdeja et al., 2019; Cohen et al., 2019; Madduri et al., 2019; Raje 


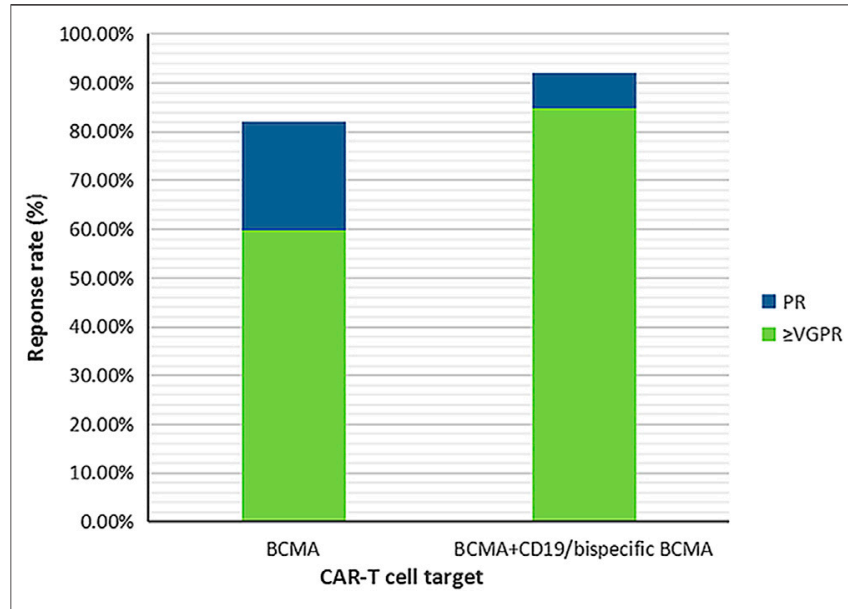

FIGURE 4 | The remission depth achieved by different target selection.

et al., 2019) (Jiang et al., 2018) (Figure 5). Hematologic toxic effects were the most frequent treatment-related AEs of grade 3 or higher, including a decreased neutrophil count (70\%, 95\% CL: 57-81\%), anemia (43\%, 95\% CL: 25-64\%), decreased lymphocyte count (43\%, 95\% CL: $16-75 \%)$, and thrombocytopenia (36\%, 95\% CL: $25-50 \%)$.

Subgroup analysis of any-grade CRS by target selection showed that any grade CRS was less frequent in the case of specific BCMA targeting (69.73\%) compared to BCMA + CD19/dual BCMA targeting (89.78\%) (interaction $p<0.05$ ). However, subgroup analysis of grade $\geq 3$ CRS by target selection suggested that, no difference occurred between specific BCMA and BCMA + CD19/ dual BCMA targeting. Additional details are shown in Table 6.

\subsection{Sensitivity Analysis}

Sensitivity analysis showed that after removal of the largest sample size among all studies, the pooled ORR did not change significantly. Moreover, the results of the meta-analysis were stable (Table 7).

\section{DISCUSSION}

In the last decade, CAR-T therapies have been extensively developed for the advancement of individualized clinical cancer immunotherapy. This meta-analysis, which examined 27 prospective studies involving 497 patients, has demonstrated that CAR-T therapy offered promising outcomes with a tolerable safety profile in RRMM patients.

Our meta-analysis suggests that CAR-T cell therapy could address the negative effects associated with high-risk cytogenetics ( $\leq 50 \%$ vs. $>50 \%=84.21 \%$ vs. $82.17 \%)$ and exhibited a higher efficacy against MM resistant to previous therapies including IMiDs, PIs, anti-CD38 monoclonal antibody, and ASCT. Notably, patients who did not receive prior ASCT achieved a better response, suggesting that ASCT is an irreplaceable component of RRMM patient treatment.

CAR-T cell-based therapies mechanistically differ from all other MM treatment modalities. CAR-T cells can be optimized to specifically kill tumor cells, or reshape the tumor microenvironment by releasing soluble factors capable of regulating the function of matrix or immune cells (Fujiwara, 2014; Maus et al., 2014; Park et al., 2016). Hence, they represent a powerful tool for targeting multiple constituents of the tumor ecological system (Ye et al., 2018). When stimulated by primary MM cells, anti-BCMA-CAR-transduced T cells produce IFN- $\gamma$ and kill them. In fact, serum from patients receiving BCMAspecific CAR-T cells kill target cells that express BCMA in vitro through complement-mediated lysis and antibody-dependent cytotoxicity (Bellucci et al., 2005). Some studies also suggest that earlier CAR-T intervention, at a stage when $\mathrm{T}$ cells may be intrinsically "fitter," may be particularly effective (Kay et al., 2001; Dhodapkar et al., 2003; Suen et al., 2016). Based on these arguments, deciding whether CAR-T therapy should be administered early is challenging, particularly for patients with unfavorable cytogenetics.

Additionally, the efficacy appeared to be independent of conditioning scheme, as the combination of cyclophosphamide/fludarabine (Cy-Flu) appears to produce CAR-T cell dynamics similar to that of cyclophosphamide alone. This differed from the CD19-specific CAR-T cell-based therapy in relapsed/refractory B cell non-Hodgkin's lymphoma, where $\mathrm{Cy} / \mathrm{Flu}$ lymphodepletion resulted in higher response rates (50\% CR, 72\% ORR) compare to those elicited by the Cy-based lymphodepletion without Flu ( $8 \%$ CR, 50\% ORR) (Turtle et al., 2016b). Our research demonstrates that the normal expansion and activity of CAR-T cells in MM may not require exhaustive lymphatic depletion, as patients with MM may have intrinsically "fitter" T cell reserves compared to patients with B cell non-

TABLE 5 | The subgroup analysis results of response depth.

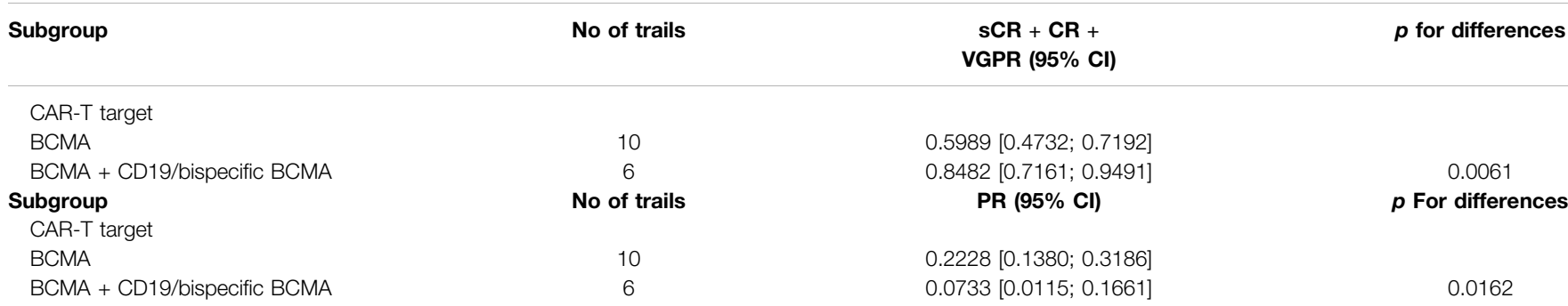




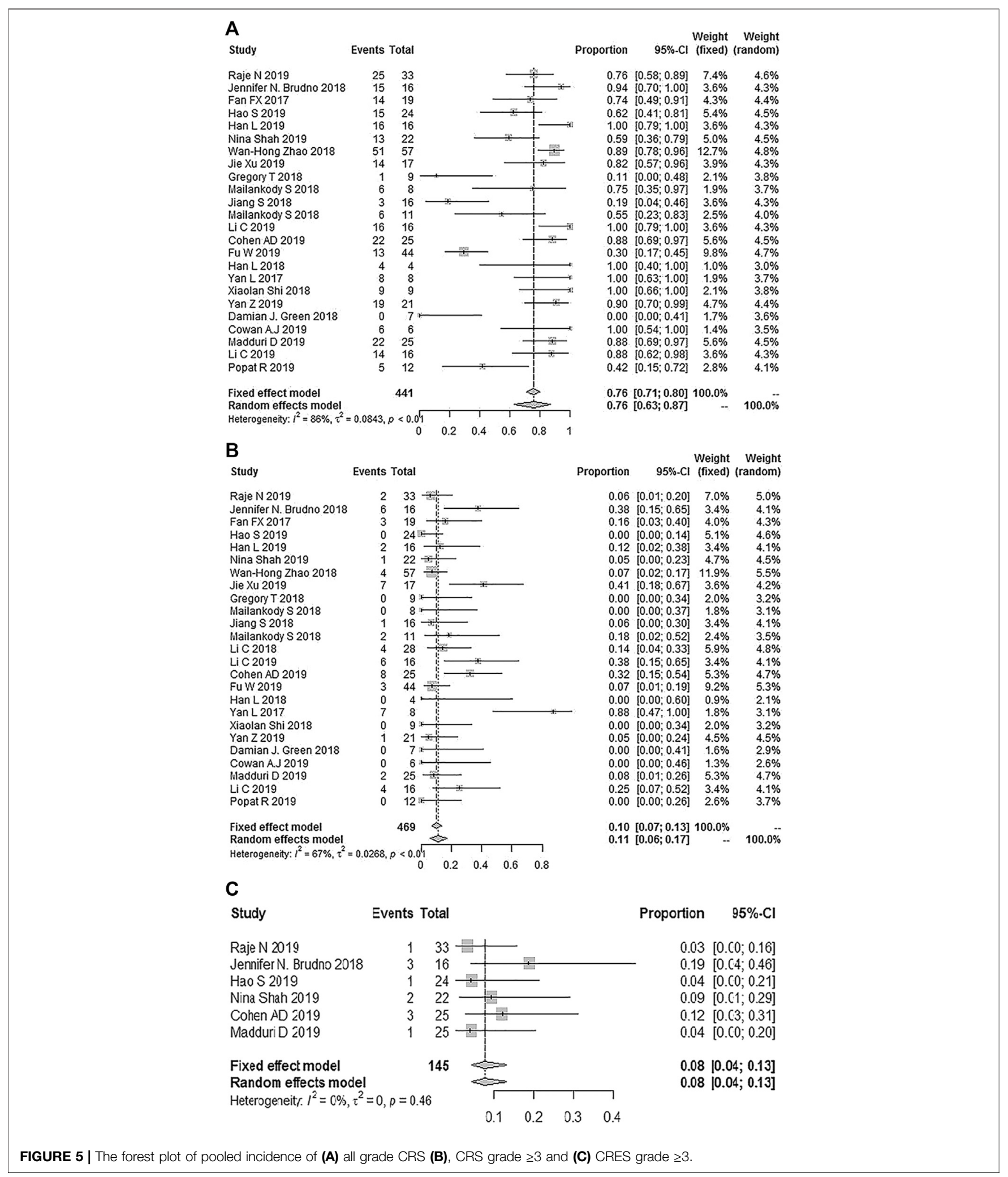

Hodgkin's lymphoma. Therefore, a single CAR-T conditioning protocol may be applied in future patient management.

Previous studies have suggested that specific product features, including the design of engineered costimulation, may impact therapeutic efficacy (Long et al., 2015; Zhao et al., 2015). In contrast, our present study showed that a similar overall response rate (ORR) was elicited by different costimulatory domains (4$1 \mathrm{BB}, \mathrm{CD} 28$, and $\mathrm{CD} 28$ plus $\mathrm{OX} 40$ ), which may indicate that the 
TABLE 6 | The subgroup analysis results of all grade CRS and severe CRS.

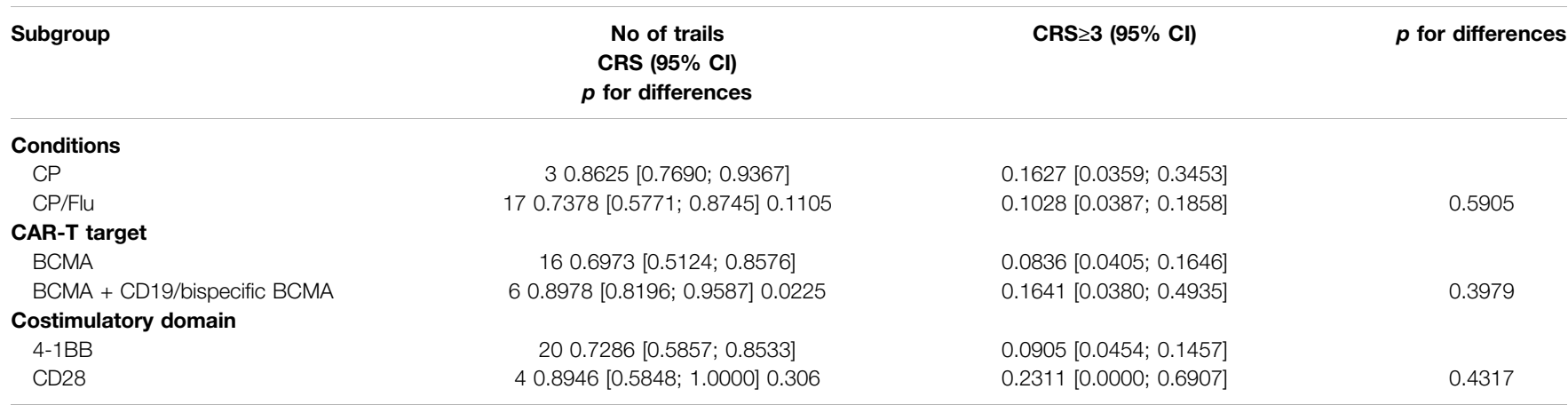

small patient samples sizes, as well as the diverse differences in study designs, including the inclusion criteria, broad range of efficacious doses, treatment schedule, and lymphodepletion regimen, preclude drawing definitive conclusions. Notably, the production of CAR-T cells depends, to a large extent, on numerous manual, open-process procedures, and cell culture media to reach a clinical therapeutic dosage (Sadelain, 2009; Sadelain et al., 2013). These characteristics may limit the application of this approach to large-scale, multicenter clinical trials. Therefore, studies are needed to streamline and optimize the production process. Moreover, additional steps should be standardized to maximize the process consistency (Roberts et al., 2018).

The initial success of the CD19-targeted CAR-T cell therapy in B-cell malignancy emphasizes that selecting the optimal surface target antigens is critical for efficient CAR-T cell therapeutics. However, first-rank surface antigens remain to be identified in MM. Nevertheless, several alternative antigens have been used in CAR-T cell therapy against MM (Bolli et al., 2014; Tai et al., 2016). In our study, the BCMA, dual BCMA, CD196, CD38, TACI, and FHVH were considered. The results show that LCARB38M and combined CD19/BCMA exhibit higher overall response rates and deeper responses compared to specific BCMA. In the design of LCAR-B38M, the antigen recognition portion consists of two camel antibody heavy chains against two BCMA epitopes. This structure may enhance the antigen recognition specifically as well as the affinity of CAR-T cells for antigen, resulting in a stronger anti-MM effect (Shah et al., 2020). In terms of immunophenotype, the dominant clones of most myeloma patients are similar to the most differentiated normal plasma cell subset: CD38 + CD138 + CD19- . A few MM clone subsets with poorly differentiated plasma cell phenotypes $\left(\mathrm{CD} 138 \mathrm{lo} /-\right.$ or $\left.\mathrm{CD} 19^{+}\right)$, or a B cell phenotype (CD138-CD19+ $\mathrm{CD} 20^{+}$) can also be found in patients. Moreover, according to a clinical trial and in vitro study using immunodeficient mice, poorly differentiated components in MM clones are also involved in disease pathogenesis. In addition, CD19 was found to be expressed on only a small proportion of myeloma cells (Bagg et al., 1989; Paiva et al., 2017; Garfall et al., 2018; Nerreter et al., 2019). Hence, the combination of CD19 and BCMA may tackle MM pathogenesis more effectively and result in enhanced antitumor effects.
TABLE 7 | The effect of removing the largest sample size of the study in the sensitivity analysis.

\begin{tabular}{lc}
\hline $\begin{array}{l}\text { Study } \\
\text { No. of patients }\end{array}$ & Proportion 95\%-Cl \\
\hline Total 497 & \\
\hline Omitting Zhang et al., 2017, 440 & $0.8800[0.8300 ; 0.9403]$ \\
\hline
\end{tabular}

Although our study included some patients without an MRD status reported, the high rate of pooled MRD negativity in patients (81\%, 67\%-91\%) was inspiring. In contrast, a recent study exploring the effects of daratumumab plus pomalidomide-dexamethasone for RRMM showed that $35 \%$ and $29 \%$ of the patients could be assessed as MRD negative at a threshold of $10^{-4}$ and $10^{-5}$ nucleated cells, respectively (Chari et al., 2017). Meanwhile, previous studies showed that the MRD status was one of the most relevant independent prognostic factors in MM. Compared with patients achieving CR who are MRD positive, patients who are MRD negative may have longer overall, and progression-free survival (PFS) (Paiva et al., 2015; Kumar et al., 2016; Munshi et al., 2017). Despite the high response rate, it remains unknown whether CAR-T cells have the potential to induce long-lasting remission in RRMM, as observed with the CD19 CAR-T cells in B-cell malignancy. Longer follow-ups for patients who exhibit a response and are MRD negative will be required to address this question.

CRS was determined to be primarily of grade 1 or 2 . The reported incidence of grade 3 or higher with CD19-directed CAR$\mathrm{T}$ cells was $46 \%$ with tisagenlecleucel and $13 \%$ with axicabtagene ciloleucel (Neelapu et al., 2017; Maude et al., 2018), which is higher than our results (11\%). The overall occurrence of grade three or four neurologic toxic events was also low (8\%). Generally, the safety profile was tolerable and manageable.

In conclusion, in an era in which numerous novel agents for $\mathrm{MM}$ are emerging, CAR-T cells demonstrate a high overall response and a good remission rate in heavily treated patients (Miguel et al., 2013; Lonial et al., 2016; Chen et al., 2018). However, further information regarding the durability of the CAR-T cell-based therapy is needed. Owing to the lack of control groups and the small sample sizes of the examined studies, our results require confirmation by randomized controlled trials. Finally, as continuous development of MM therapeutic agents 
is underway, the optimization of timing, sequensce, and combination with other therapies will be crucial to obtain adequate responses and substantially increase patient survival (Trudel et al., 2018; Kumar et al., 2019; Parrondo et al., 2020).

\section{DATA AVAILABILITY STATEMENT}

The original contributions presented in the study are included in the article/supplementary material, further inquiries can be directed to the corresponding author.

\section{AUTHOR CONTRIBUTIONS}

XX collected, analyzed the data, and wrote the article. QH, YO, and WW collected the data, helped in subgroup analysis and

\section{REFERENCES}

Bagg, A., Becker, P., Bezwoda, W., Rensburg, L., and Mendelow, B. (1989). Circulating monotypic B-cells in multiple myeloma: association with lambda paraproteins. Br. J. Haematol. 72 (2), 167-172. doi:10.1111/j.1365-2141.1989. tb07678.x

Bellucci, R., Alyea, E. P., Chiaretti, S., Wu, C. J., Zorn, E., Weller, E., et al. (2005). Graft-versus-tumor response in patients with multiple myeloma is associated with antibody response to BCMA, a plasma-cell membrane receptor. Blood 105 (10), 3945-3950. doi:10.1182/blood-2004-11-4463

Berdeja, J. G., Alsina, M., Shah, N. D., Siegel, D. S., Jagannath, S., Madduri, D., et al. (2019). Updated results from an ongoing phase 1 clinical study of bb21217 anti-Bcma CAR T cell therapy. Blood 134 (1), 927. doi:10.1182/ blood-2019-126660

Bolli, N., Avet-Loiseau, H., Wedge, D. C., Van Loo, P., Alexandrov, L. B., Martincorena, I., et al. (2014). Heterogeneity of genomic evolution and mutational profiles in multiple myeloma. Nat. Commun. 5, 2997. doi:10. 1038/ncomms3997

Brudno, J. N., Maric, I., Hartman, S. D., Rose, J. J., Wang, M., Lam, N., et al. (2018). $\mathrm{T}$ cells genetically modified to express an anti-B-cell maturation antigen chimeric antigen receptor cause remissions of poor-prognosis relapsed multiple myeloma. J. Clin. Oncol. 36(22), 2267-2280. doi:10.1200/jco.2018. 77.8084

Chari, A., Suvannasankha, A., Fay, J. W., Arnulf, B., Kaufman, J. L., Ifthikharuddin, J. J., et al. (2017). Daratumumab plus pomalidomide and dexamethasone in relapsed and/or refractory multiple myeloma. Blood 130 (8), 974-981. doi:10. 1182/blood-2017-05-785246

Chen, C., Siegel, D., Gutierrez, M., Jacoby, M., Hofmeister, C. C., Gabrail, N., et al. (2018). Safety and efficacy of selinexor in relapsed or refractory multiple myeloma and Waldenstrom macroglobulinemia. Blood 131 (8), 855-863. doi:10.1182/blood-2017-08-797886

Chen, J., Chen, L. J., Yang, S. S., Sun, Y., Wu, W., Liu, Y. F., et al. (2019). Exploratory trial of a biepitopic CAR T-targeting B cell maturation antigen in relapsed/refractory multiple myeloma. Proc. Natl. Acad. Sci. USA 116 (19), 9543-9551. doi:10.1073/pnas.1819745116

Chim, C. S., Kumar, S. K., Orlowski, R. Z., Cook, G., Richardson, P. G., Gertz, M. A., et al. (2018). Management of relapsed and refractory multiple myeloma: novel agents, antibodies, immunotherapies and beyond. Leukemia 32 (2), 252-262. doi:10.1038/leu.2017.329

Cohen, A. D., Garfall, A. L., Stadtmauer, E. A., Melenhorst, J. J., Lacey, S. F., Lancaster, E., et al. (2019). B cell maturation antigen-specific CAR T cells are clinically active in multiple myeloma. J. Clin. Invest. 129 (6), 2210-2221. doi:10. 1172/jci126397

Costello, C. L., Gregory, T. K., Abbas Ali, S., Berdeja, J. G., Patel, K. K., Shah, N. D., et al. (2019). Phase 2 study of the response and safety of p-BCMA-101 CAR-T prepared the figures and tables. YW and QH designed research, provided the plan and modified the manuscript. All authors read and approved the final manuscript.

\section{FUNDING}

This research was funded by the National Natural Science Foundation of China (81470327), Sichuan Provincial Academic and Technical Leadership Support Funding Project (2018RZ0137).

\section{ACKNOWLEDGMENTS}

The authors thank WW of The Chinese Cochrane Center for her considerable assistance with methodology.

cells in patients with relapsed/refractory (R/R) multiple myeloma (MM) (PRIME). Blood 134 (1), 3184. doi:10.1182/blood-2019-129562

Cowan, A. J., Pont, M., Sather, B. D., Turtle, C. J., Till, B. G., Nagengast, A. M., et al. (2019). Efficacy and safety of fully human bcma CAR T cells in combination with a gamma secretase inhibitor to increase Bcma surface expression in patients with relapsed or refractory multiple myeloma. Blood 134 (1), 204. doi:10.1182/blood-2019-129405

Cullis, P. S., Siminas, S., and Losty, P. D. (2020). Efficacy of antireflux surgery in children with or without neurological impairment: a systematic review. $\mathrm{Br}$. J. Surg. 107, 636. doi:10.1002/bjs.11488

Damian, J. (2018). Green, margot pont, blythe duke sather, et al. fully human bcma targeted chimeric antigen receptor $t$ cells administered in a defined composition demonstrate potency at low doses in advanced stage high risk multiple myeloma. Blood 132 (Suppl. 1), 1011. doi:10.1182/blood-2018-99-117729

Dhodapkar, M. V., Krasovsky, J., Osman, K., and Geller, M. D. (2003). Vigorous premalignancy-specific effector $\mathrm{T}$ cell response in the bone marrow of patients with monoclonal gammopathy. J. Exp. Med. 198 (11), 1753-1757. doi:10.1084/ jem. 20031030

Fan, F. X., Zhao, W., Liu, J., He, A., Chen, Y., Cao, X., et al. (2017). A potential terminator of multiple myeloma: myeloma: lCAR-B38M CAR-T cells achieved unprecedented high rate of continuous complete remission (CCR) in refractory or relapsed multiple myeloma patients. Mol. Ther. 25 (5), 334.

Fu, W., Du, J., Jiang, H., Cheng, Z., Wei, R., Yu, K., et al. (2019). Efficacy and safety of CAR-T therapy with safety switch targeting BCMA for patients with relapsed/refractory multiple myeloma in a phase 1 clinical study. Blood 134 (Suppl. 1), 3154. doi:10.1182/blood-2019-127608

Fujiwara, H. (2014). Adoptive T-cell therapy for hematological malignancies using $\mathrm{T}$ cells gene-modified to express tumor antigen-specific receptors. Int. J. Hematol. 99 (2), 123-131. doi:10.1007/s12185-013-1493-7

Garfall, A. L., Stadtmauer, E. A., Hwang, W.-T., Lacey, S. F., Melenhorst, J. J., Krevvata, M., et al. (2018). Anti-CD19 CAR T cells with high-dose melphalan and autologous stem cell transplantation for refractory multiple myeloma. JCI Insight 3 (8), e120505. doi:10.1172/jci.insight.120505

Goldschmidt, H., Ashcroft, J., Szabo, Z., and Garderet, L. (2019). Navigating the treatment landscape in multiple myeloma: which combinations to use and when? Ann. Hematol. 98 (1), 1-18. doi:10.1007/s00277-018-3546-8

Gregory, T. K., Berdeja, J. G., Patel, K. K., Ali, S. A., Cohen, A. D., Costello, C., et al. (2018). Abstract CT130: clinical trial of P-BCMA-101 T stem cell memory (Tscm) CAR-T cells in relapsed/refractory $(\mathrm{r} / \mathrm{r})$ multiple myeloma (MM) Cancer Res. 78 (13 Suppl. 1). doi:10.1158/15387445.AM2018-CT130

Guedan, S., Calderon, H., Posey, A. D., Jr., and Maus, M. V. (2019). Engineering and design of chimeric antigen receptors. Mol. Ther. Methods Clin. Dev. 12, 145-156. doi:10.1016/j.omtm.2018.12.009

Hajek, R., Okubote, S. A., and Svachova, H. (2013). Myeloma stem cell concepts, heterogeneity and plasticity of multiple myeloma. Br. J. Haematol. 163 (5), 551-564. doi:10.1111/bjh. 12563 
Han, L., Gao, Q., Zhou, K., Yin, Q., Fang, B., Zhou, J., et al. (2018). Development and evaluation of CART targeting Bcma with humanized alpaca-derived singledomain antibody as antigen recognition domain. Blood 132 (Suppl. 1), 1976. doi:10.1182/blood-2018-99-114980

Han, L., Gao, Q., Zhou, K., Zhou, J., Fang, B., Zhang, J., et al. (2019). The phase I clinical study of CART targeting BCMA with humanized alpaca-derived singledomain antibody as antigen recognition domain. J. Clin. Oncol. 37 (Suppl. 15), 2535. doi:10.1200/jco.2019.37.15_suppl.2535

Hao, S., Jie, J., Jiang, S., Li, Z., Yang, M., Zhang, W., et al. (2019). Phase 1 trial of the safety and efficacy of fully human anti-bcma car T cells in relapsed/refractory multiple myeloma. Blood 134 (Suppl. 1). doi:10.1182/blood-2019-126104

Jain, M. D., Bachmeier, C. A., Phuoc, V. H., and Chavez, J. C. (2018). Axicabtagene ciloleucel (KTE-C19), an anti-CD19 CAR T therapy for the treatment of relapsed/refractory aggressive B-cell non-Hodgkin's lymphoma. Ther. Clin. Risk Manag. 14, 1007-1017. doi:10.2147/TCRM.S145039

Jensen, M. C. and Riddell, S. R. (2015). Designing chimeric antigen receptors to effectively and safely target tumors. Curr. Opin. Immunol. 33, 9-15. doi:10. 1016/j.coi.2015.01.002

Jiang, S., Jin, J., Hao, S., Yang, M., Chen, L., Ruan, H., et al. (2018). Low dose of human scFv-derived BCMA-targeted CAR-T cells achieved fast response and high complete remission in patients with relapsed/refractory multiple myeloma. Blood 132 (Suppl. 1), 960. doi:10.1182/blood-2018-99-113220

Jie, J., Hao, S., Jiang, S., Li, Z., Yang, M., Zhang, W., et al. (2019). Phase 1 trial of the safety and efficacy of fully human anti-bcma car $\mathrm{T}$ cells in relapsed/refractory multiple myeloma. Blood 134 (Suppl. 1), 4435. doi:10.1182/blood-2019-126104

Kay, N. E., Leong, T. L., Bone, N., Vesole, D. H., Greipp, P. R., Van Ness, B., et al. (2001). Blood levels of immune cells predict survival in myeloma patients: results of an Eastern Cooperative Oncology Group phase 3 trial for newly diagnosed multiple myeloma patients. Blood 98 (1), 23-28. doi:10.1182/blood. v98.1.23

Knobloch, K., Yoon, U., and Vogt, P. M. (2011). Preferred reporting items for systematic reviews and meta-analyses (PRISMA) statement and publication bias. J. Cranio-Maxillofacial Surg. 39 (2), 91-92. doi:10.1016/j. jcms.2010.11.001

Kochenderfer, J. N., Somerville, R. P. T., Lu, T., Yang, J. C., Sherry, R. M., Feldman, S. A., et al. (2017). Long-duration complete remissions of diffuse large B cell lymphoma after anti-CD19 chimeric antigen receptor T cell therapy. Mol. Ther. 25 (10), 2245-2253. doi:10.1016/j.ymthe.2017.07.004

Kumar, S. K., Buadi, F. K., and Rajkumar, S. V. (2019). Pros and cons of frontline autologous transplant in multiple myeloma: the debate over timing. Blood 133 (7), 652-659. doi:10.1182/blood-2018-08-825349

Kumar, S., Paiva, B., Anderson, K. C., Durie, B., Landgren, O., Moreau, P., et al. (2016). International Myeloma Working Group consensus criteria for response and minimal residual disease assessment in multiple myeloma. Lancet Oncol. 17 (8), e328-e346. doi:10.1016/S1470-2045(16)30206-6

Lam, N., Trinklein, N. D., Buelow, B., Patterson, G. H., Ojha, N., and Kochenderfer, J. N. (2020). Anti-BCMA chimeric antigen receptors with fully human heavychain-only antigen recognition domains. Nat. Commun. 11 (1), 283. doi:10. 1038/s41467-019-14119-9

Lee, D. W., Kochenderfer, J. N., Stetler-Stevenson, M., Cui, Y. K., Delbrook, C., Feldman, S. A., et al. (2015). T cells expressing CD19 chimeric antigen receptors for acute lymphoblastic leukaemia in children and young adults: a phase 1 doseescalation trial. Lancet 385 (9967), 517-528. doi:10.1016/S0140-6736(14) 61403-3

Li, C., Wang, Q., Zhu, H., Mao, X., Wang, Y., Zhang, Y., et al. (2018). T cells expressing anti B-cell maturation antigen chimeric antigen receptors for plasma cell malignancies. Blood 132 (Suppl. 1), 1013. doi:10.1182/blood-2018-99116898

Li, C., Mei, H., Hu, Y., Guo, T., Liu, L., Jiang, H., et al. (2019a). A bispecific CAR-T cell therapy targeting BCMA and CD38 for relapsed/refractory multiple myeloma: updated results from a phase 1 dose-climbing trial. Blood 134 (Suppl. 1), 930. doi:10.1182/blood-2019-130340

Li, C., Wang, J., Wang, D., Hu, G., Yang, Y., Zhou, X., et al. (2019b). Efficacy and safety of fully human BCMA targeting CAR $\mathrm{T}$ cell therapy in relapsed/ refractory multiple myeloma. Blood 134 (Suppl. 1), 929. doi:10.1182/blood2019-128468

Lipe, B., Vukas, R., and Mikhael, J. (2016). The role of maintenance therapy in multiple myeloma. Blood Canc. J. 6(10), e485. doi:10.1038/bcj.2016.89
Long, A. H., Haso, W. M., Shern, J. F., Wanhainen, K. M., Murgai, M., Ingaramo, M., et al. (2015). 4-1BB costimulation ameliorates T cell exhaustion induced by tonic signaling of chimeric antigen receptors. Nat. Med. 21(6), 581-590. doi:10. 1038/nm.3838

Lonial, S., Weiss, B. M., Usmani, S. Z., Singhal, S., Chari, A., Bahlis, N. J., et al. (2016). Daratumumab monotherapy in patients with treatment-refractory multiple myeloma (SIRIUS): an open-label, randomised, phase 2 trial. Lancet 387 (10027), 1551-1560. doi:10.1016/S0140-6736(15)01120-4

Madduri, D., Usmani, S. Z., Jagannath, S., Singh, I., Zudaire, E., Yeh, T. M., et al. (2019). Results from CARTITUDE-1: a phase 1b/2 study of JNJ-4528, a CAR-T cell therapy directed against B-cell maturation antigen (BCMA), in patients with relapsed and/or refractory multiple myeloma (R/R MM). Blood 134 (1), 527. doi:10.1182/blood-2019-121731

Mailankody, S., Htut, M., Lee, K. P., Bensinger, W., Devries, T., Piasecki, J., et al. (2018a). JCARH125, anti-BCMA CAR T-cell therapy for relapsed/refractory multiple myeloma: initial proof of concept results from a phase $1 / 2$ multicenter study (EVOLVE). Blood 132, 957. doi:10.1182/blood-2018-99-113548

Mailankody, S., Ghosh, A., Staehr, M., Purdon, T. J., Roshal, M., Halton, E., et al. (2018b). Clinical responses and pharmacokinetics of MCARH171, a humanderived Bcma targeted CAR T cell therapy in relapsed/refractory multiple myeloma: final results of a phase I clinical trial. Blood 132 (Suppl. 1), 959. doi:10. 1182/blood-2018-99-119717

Makita, S., Yoshimura, K., and Tobinai, K. (2017). Clinical development of antiCD19 chimeric antigen receptor T-cell therapy for B-cell non-Hodgkin lymphoma. Canc. Sci. 108 (6), 1109-1118. doi:10.1111/cas.13239

Maude, S. L., Frey, N., Shaw, P. A., Aplenc, R., Barrett, D. M., Bunin, N. J., et al. (2014). Chimeric antigen receptor T cells for sustained remissions in leukemia. N. Engl. J. Med. 371 (16), 1507-1517. doi:10.1056/NEJMoa1407222

Maude, S. L., Laetsch, T. W., Buechner, J., Rives, S., Boyer, M., Bittencourt, H., et al. (2018). Tisagenlecleucel in children and young adults with B-cell lymphoblastic leukemia. N. Engl. J. Med. 378 (5), 439-448. doi:10.1056/NEJMoa1709866

Maus, M. V., Grupp, S. A., Porter, D. L., and June, C. H. (2014). Antibody-modified $\mathrm{T}$ cells: CARs take the front seat for hematologic malignancies. Blood 123 (17), 2625-2635. doi:10.1182/blood-2013-11-492231

Melchor, L., Brioli, A., Wardell, C. P., Murison, A., Potter, N. E., Kaiser, M. F., et al. (2014). Single-cell genetic analysis reveals the composition of initiating clones and phylogenetic patterns of branching and parallel evolution in myeloma. Leukemia 28 (8), 1705-1715. doi:10.1038/leu.2014.13

Miguel, J. S., Weisel, K., Moreau, P., Lacy, M., Song, K., Delforge, M., et al. (2013). Pomalidomide plus low-dose dexamethasone versus high-dose dexamethasone alone for patients with relapsed and refractory multiple myeloma (MM-003): a randomised, open-label, phase 3 trial. Lancet Oncol. 14 (11), 1055-1066. doi:10. 1016/S1470-2045(13)70380-2

Mikkilineni, L. and Kochenderfer, J. N. (2017). Chimeric antigen receptor T-cell therapies for multiple myeloma. Blood 130 (24), 2594-2602. doi:10.1182/blood2017-06-793869

Mikkilineni, L., Manasanch, E. E., Lam, N., Vanasse, D., Brudno, J. N., Maric, I., et al. (2019). T cells expressing an anti-b-cell maturation antigen (BCMA) chimeric antigen receptor with a fully-human heavy-Chain-only antigen recognition domain induce remissions in patients with relapsed multiple myeloma. Blood 134 (Suppl. 1), 3230. doi:10.1182/blood-2019-129088

Munshi, N. C., Avet-Loiseau, H., Rawstron, A. C., Owen, R. G., Child, J. A., Thakurta, A., et al. (2017). Association of minimal residual disease with superior survival outcomes in patients with multiple myeloma. JAMA Oncol. 3 (1), 28-35. doi:10.1001/jamaoncol.2016.3160

Neelapu, S. S., Locke, F. L., Bartlett, N. L., Lekakis, L. J., Miklos, D. B., Jacobson, C. A., et al. (2017). Axicabtagene ciloleucel CAR T-cell therapy in refractory large B-cell lymphoma. N. Engl. J. Med. 377 (26), 2531-2544. doi:10.1056/ NEJMoa1707447

Neelapu, S. S., Locke, F. L., and Go, W. Y. (2018). CAR T-cell therapy in large B-cell lymphoma. N. Engl. J. Med. 378 (11), 1065. doi:10.1056/NEJMc1800913.

Nerreter, T., Letschert, S., Götz, R., Doose, S., Danhof, S., Einsele, H., et al. (2019). Super-resolution microscopy reveals ultra-low CD19 expression on myeloma cells that triggers elimination by CD19 CAR-T. Nat. Commun. 10 (1), 3137. doi:10.1038/s41467-019-10948-w

Paiva, B., Puig, N., Puig, N., Cedena, M. T., de Jong, B. G., Ruiz, Y., et al. (2017). Differentiation stage of myeloma plasma cells: biological and clinical significance. Leukemia 31 (2), 382-392. doi:10.1038/leu.2016.211 
Paiva, B., van Dongen, J. J. M., and Orfao, A. (2015). New criteria for response assessment: role of minimal residual disease in multiple myeloma. Blood 125 (20), 3059-3068. doi:10.1182/blood-2014-11-568907

Palumbo, A. and Anderson, K. (2011). Multiple myeloma. N. Engl. J. Med. 364(11), 1046-1060. doi:10.1056/NEJMra1011442

Park, J. H., Geyer, M. B., and Brentjens, R. J. (2016). CD19-targeted CAR T-cell therapeutics for hematologic malignancies: interpreting clinical outcomes to date. Blood 127 (26), 3312-3320. doi:10.1182/blood-2016-02-629063

Park, J. H., Rivière, I., Gonen, M., Wang, X., Sénéchal, B., Curran, K. J., et al. (2018). Long-term follow-up of CD19 CAR therapy in acute lymphoblastic leukemia. N. Engl. J. Med. 378 (5), 449-459. doi:10.1056/NEJMoa1709919

Parrondo, R. D., Ailawadhi, S., Sher, T., Chanan-Khan, A. A., and Roy, V. (2020). Autologous stem-cell transplantation for multiple myeloma in the era of novel therapies. J. Oncol. Pract. 16 (2), 56-66. doi:10.1200/jop.19.00335

Popat, R., Zweegman, S., Cavet, J., Yong, K., Lee, L., Faulkner, J., et al. (2019). Phase 1 first-in-human study of AUTO2, the first chimeric antigen receptor (CAR) $\mathrm{T}$ cell targeting april for patients with relapsed/refractory multiple myeloma (RRMM). Blood 134 (Suppl. 1), 3112. doi:10.1182/blood-2019-126689

Raje, N., Berdeja, J., Lin, Y., Siegel, D., Jagannath, S., Madduri, D., et al. (2019). Anti-BCMA CAR T-cell therapy bb2121 in relapsed or refractory multiple myeloma. N. Engl. J. Med. 380 (18), 1726-1737. doi:10.1056/NEJMoa1817226

Rajkumar, S. V. (2011). Treatment of multiple myeloma. Nat. Rev. Clin. Oncol. 8 (8), 479-491. doi:10.1038/nrclinonc.2011.63

Roberts, Z. J., Better, M., Bot, A., Roberts, M. R., and Ribas, A. (2018). Axicabtagene ciloleucel, a first-in-class CAR $\mathrm{T}$ cell therapy for aggressive NHL. Leuk. Lymphoma 59 (8), 1785-1796. doi:10.1080/10428194.2017.1387905

Sadelain, M., Brentjens, R., and Rivière, I. (2013). The basic principles of chimeric antigen receptor design. Canc. Discov. 3 (4), 388-398. doi:10.1158/2159-8290. cd-12-0548

Sadelain, M. (2009). T-cell engineering for cancer immunotherapy. Canc. J. 15 (6), 451-455. doi:10.1097/PPO.0b013e3181c51f37

Shah, N., Chari, A., Scott, E., Mezzi, K., and Usmani, S. Z. (2020). B-cell maturation antigen (BCMA) in multiple myeloma: rationale for targeting and current therapeutic approaches. Leukemia 34 (4), 985-1005. doi:10.1038/s4137541020-40734-z10.1038/s41375-020-0734-z

Shi, X., Yan, L., Shang, J., Qu, S., Kang, L., Zhou, J., et al. (2018). Tandom autologous transplantation and combined infusion of CD19 and Bcma-specific chimeric antigen receptor $\mathrm{T}$ cells for high risk MM: initial safety and efficacy report from a clinical pilot study. Blood 132 (Suppl. 1). doi:10.1182/blood-2018-99-117964

Slim, K., Nini, E., Forestier, D., Kwiatkowski, F., Panis, Y., and Chipponi, J. (2003). Methodological index for non-randomized studies (MINORS): development and validation of a new instrument. ANZ J. Surg. 73 (9), 712-716. doi:10.1046/j. 1445-2197.2003.02748.x

Suen, H., Brown, R., Yang, S., Weatherburn, C., Ho, P. J., Woodland, N., et al. (2016). Multiple myeloma causes clonal T-cell immunosenescence: identification of potential novel targets for promoting tumour immunity and implications for checkpoint blockade. Leukemia 30 (8), 1716-1724. doi:10.1038/leu.2016.84

Tai, Y.-T., Acharya, C., An, G., Moschetta, M., Zhong, M. Y., Feng, X., et al. (2016). APRIL and BCMA promote human multiple myeloma growth and immunosuppression in the bone marrow microenvironment. Blood 127 (25), 3225-3236. doi:10.1182/blood-2016-01-691162
Trudel, S., Lendvai, N., Popat, R., Voorhees, P. M., Reeves, B., Libby, E. N., et al. (2018). Targeting B-cell maturation antigen with GSK2857916 antibody-drug conjugate in relapsed or refractory multiple myeloma (BMA117159): a dose escalation and expansion phase 1 trial. Lancet Oncol. 19 (12), 1641-1653. doi:10.1016/S1470-2045(18)30576-X

Turtle, C. J., Hanafi, L.-A., Berger, C., Gooley, T. A., Cherian, S., Hudecek, M., et al. (2016a). CD19 CAR-T cells of defined CD4+: CD8+ composition in adult B cell ALL patients. J. Clin. Invest. 126 (6), 2123-2138. doi:10.1172/JCI85309

Turtle, C. J., Hanafi, L.-A., Berger, C., Hudecek, M., Pender, B., Robinson, E., et al. (2016b). Immunotherapy of non-Hodgkin's lymphoma with a defined ratio of CD8+ and CD4 + CD19-specific chimeric antigen receptor-modified T cells. Sci. Transl. Med. 8 (355), 355ra116. doi:10.1126/scitranslmed.aaf8621

van der Stegen, S. J. C., Hamieh, M., and Sadelain, M. (2015). The pharmacology of second-generation chimeric antigen receptors. Nat. Rev. Drug Discov. 14 (7), 499-509. doi:10.1038/nrd4597

Yan, L., Shang, J., Kang, L., Shi, X., Zhou, J., Jin, S., et al. (2017). Combined infusion of CD19 and BCMA-specific chimeric antigen receptor t cells for RRMM: initial safety and efficacy report from a clinical pilot study. Blood 130 (Suppl. 1), 506. doi:10.1182/blood.V130.Suppl_1.506.506

Yan, Z., Cao, J., Cheng, H., Qiao, J., Zhang, H., Wang, Y., et al. (2019). A combination of humanised anti-CD19 and anti-BCMA CAR T cells in patients with relapsed or refractory multiple myeloma: a single-arm, phase 2 trial. Lancet Haematol. 6 (10), e521-e529. doi:10.1016/s23523026(19)30115-2

Ye, B., Stary, C. M., Li, X., Gao, Q., Kang, C., and Xiong, X. (2018). Engineering chimeric antigen receptor-T cells for cancer treatment. Mol. Canc. 17 (1), 32. doi:10.1186/s12943-018-0814-0

Zhang, W., Zhao, W., Liu, J., He, A., Chen, Y., Cao, X., et al. (2017). Phase I, openlabel trial of anti-bcma chimeric antigen receptor $\mathrm{T}$ cells in patients with relapsed/refractory multiple myeloma. Haematologica 102, 2-3. doi:10.3324/ haematol.2016.158865

Zhao, W. H., Liu, J., Wang, B. Y., Chen, Y. X., Cao, X. M., and Yang, Y., (2018). A phase 1, open-label study of LCAR-B38M, a chimeric antigen receptor $\mathrm{T}$ cell therapy directed against $\mathrm{B}$ cell maturation antigen, in patients with relapsed or refractory multiple myeloma. J. Hematol. Oncol. 11 (1), 141. doi:10.1186/ s13045-018-0681-6

Zhao, Z., Condomines, M., van der Stegen, S. J. C., Perna, F., Kloss, C. C., Gunset, G., et al. (2015). Structural design of engineered costimulation determines tumor rejection kinetics and persistence of CAR T cells. Canc. Cell 28 (4), 415-428. doi:10.1016/j.ccell.2015.09.004

Conflict of Interest: The authors state that the research was performed in the absence of any commercial or financial relationships that could be construed as a potential conflict of interest.

Copyright (C) 2020 Xiang, He, Ou, Wang and Wu. This is an open-access article distributed under the terms of the Creative Commons Attribution License (CC BY). The use, distribution or reproduction in other forums is permitted, provided the original author(s) and the copyright owner(s) are credited and that the original publication in this journal is cited, in accordance with accepted academic practice. No use, distribution or reproduction is permitted which does not comply with these terms. 